\title{
The effects of current production techniques on the surface roughness, oxide layer thickness and porcelain bond strength of cobalt-chromium and titanium substructures
}

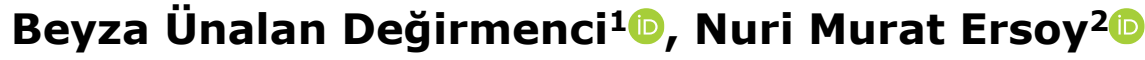 \\ ${ }^{1}$ Van Yüzüncü Yıl University, Faculty of Dentistry, Department of Prosthodontics, Van, Turkey \\ 2 Turkey Ministry of Health, Alanya Oral Health Center, Antalya, Turkey
}

\section{Correspondence:}

\section{Dr. Beyza ÜNALAN DEĞiRMENCi}

Van Yüzüncü Yıl University, Faculty of

Dentistry, Department of

Prosthodontics, Van, Turkey.

E-mail:beyzaunalan@hotmail.com

Received: 15 October 2021

Accepted: 15 December 2021

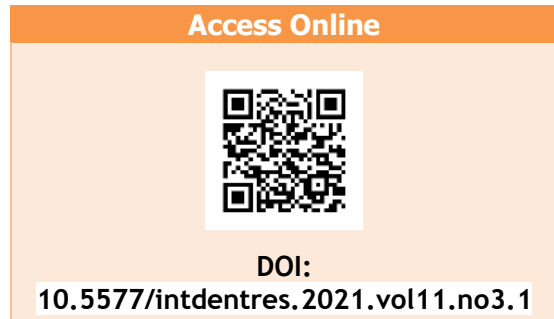

10.5577/intdentres.2021.vol11.no3.1

\section{Abstract}

Aim: This study aimed to evaluate the oxide layer, surface roughness, and bond strength with porcelain of cobalt-chromium ( $\mathrm{Co}-\mathrm{Cr}$ ) and titanium (Ti) substructures produced using casting, milling and selective laser sintering techniques.

Methodology: A total of 180 disc-shaped metal samples with a diameter of $1 \mathrm{~cm}$ and a thickness of $3 \mathrm{~mm}$ were produced. The samples were divided into six groups $(n=15)$ according to the technique used to produce the metal substructures-casting, milling, and SLS-and the chemical composition of the metal substructure- $\mathrm{Co}-\mathrm{Cr}$ and $\mathrm{Ti}$. Then roughness averages $(\mathrm{Ra})$ of the sample surfaced were calculated with a contact-type profilometer. Nondestructive energy-dispersive X-ray was performed to ensure that the layer displayed in contrast was the oxide layer, and the average oxide layer thickness was calculated from scanning electron microscope images. Metal-porcelain complexes were subjected to shear bond strength test and failure types were noted. Two-way multivariate analysis of variance (MANOVA) was used to compare oxide layer thickness, surface roughness, and shear bond strength according to the metal and production technique, and Tukey's honestly significant difference (HSD) test was used for multiple comparisons of the main effects.

Results: Two-way MANOVA revealed that the metal and technique used in the substructure production had significant effects on surface roughness, oxide layer thickness and shear bond strength $(\mathrm{p}<0.001) . \mathrm{Ti}$ groups exhibited thicker oxide layer formation than $\mathrm{Co}-\mathrm{Cr}$ groups. Low surface roughness values were observed in the milling groups. The highest shear bond strength value $(53.8 \mathrm{MPa})$ was observed in the $\mathrm{Co}-\mathrm{Cr}$ group produced by casting, while the lowest value $(32.2 \mathrm{MPa})$ was obtained in the Ti group produced by casting.

Conclusion: It should be kept in mind that there is no ideal production technique and that the effects of the production technique differ depending on the metal used.

Keywords: surface roughness, oxide layer thickness, bond strength, titanium, chromium, cobalt

How to cite this article: Ünalan Değirmenci B, Ersoy NM. The effects of current production techniques on the surface roughness, oxide layer thickness and porcelain bond strength of cobalt-chromium and titanium substructures. Int Dent Res 2021;11(3):129-39. https://doi.org/10.5577/intdentres.2021.vol11.no3.1 


\section{Introduction}

Porcelain-fused-to-metal restorations (PFM) have important applications in current dental treatment procedures and are widely accepted by both physicians and patients (1). Their reported superior mechanical properties, significantly lower fabrication cost compared to all-ceramic restorations, and high longterm survival rates are the main reasons for this (2). There are many noble and base metal alloys on the market that can be used in PFM production to meet user demands (3). However, the increasing cost of noble metals and the high allergenic potential of nickelchromium ( $\mathrm{Ni}-\mathrm{Cr}$ ) alloys have made cobalt-chromium (Co-Cr) alloys stand out among all these options (4). However, although $\mathrm{Co}-\mathrm{Cr}$ alloys have low density, high strength, and good thermal resistance (5), Grimaudo noted that they exhibit limited biocompatibility, which is a growing concern (6). Moreover, Buciumeanu et al. highlighted the need to address the intraoral corrosion behavior of $\mathrm{Co}-\mathrm{Cr}$ alloys, prompting the exploration of alternatives (7). This quest has led to research into titanium $(\mathrm{Ti})$, which has been proven to have high biocompatibility and excellent corrosion resistance, especially in implantology (8), and has become a preferred material in prosthetic dentistry (9).

The conventional lost-wax casting technique is frequently used in the production of metal substructures in PFM restorations (10). However, contrary to popular belief, the casting method is highly complex and technically sensitive due to the wide melting range of various metals and their sensitivity to oxidation at high temperatures (11). Titanium is a material with very low castability, low density $(4.5$ $\left.\mathrm{g} / \mathrm{cm}^{3}\right)$, and a high melting point $\left(1668^{\circ} \mathrm{C}\right)(12)$. Moreover, it interacts with the investment material during the casting process, and an alpha-case layer is formed on the surface of the material, which is associated with the absorption of oxygen, hydrogen, and nitrogen, causing low fracture resistance (13). To overcome these problems, PFMs undergo constant modifications in terms of the materials and production techniques used (14).

The rapid developments in digital technology in recent years have led to new technologies for the production of metal substructures (5). The milling method, which is a computer-aided design/computeraided manufacturing (CAD/CAM) technique, is based on the production of a designed object from prefabricated blocks by subtraction (10). It has distinct advantages over the casting technique, as it reduces the production time and post-processing needs and increases the sensitivity of the substructures (1). However, it is insufficient for the production of complex shapes and can result in a significant amount of residual material after production (9). Therefore, studies in the field of prosthetic dentistry have focused on rapid prototype production techniques (12). Selective laser sintering (SLS), which, unlike milling, is an additive method, aims to create a three-dimensional restoration by laser fusion of multiple layers of powder. Layers corresponding to virtual sections of a CAD model are locally fused to the underlying ones. Virtually no material is wasted, as the remaining powder can be used for more SLS (14). However, changes in production techniques lead to different heating and cooling conditions, which can result in variations in the microstructure of metals (15). Accordingly, in a study on $\mathrm{Co}-\mathrm{Cr}$ alloys, Qian et al. drew attention to the effects of production techniques on the mechanical properties of metals (16). Bae et al. reported that the production technique affects the surface quality of the metal, which in turn affects the porcelain bonding (17).

Few studies have evaluated the effects of production techniques on the bond strength of metal substructures with porcelain (18), and to the authors' knowledge, the metal alloys evaluated in these studies were Co-Cr. However, the evaluation of the effects of these methods on $\mathrm{Ti}$, which is a widely used substructure material, and the comparison of these results with $\mathrm{Co}-\mathrm{Cr}$ alloys are particularly important for increasing the clinical uses of titanium. To fill this research gap, this study aimed to evaluate the oxide layer, surface roughness, and bond strength with porcelain of $\mathrm{Co}-\mathrm{Cr}$ and $\mathrm{Ti}$ substructures produced using three current techniques. It was hypothesized that the metal alloy and the production technique used for the substructure would have no effect on the oxide layer and surface roughness, and therefore would have no effect on the shear bond strength between the metal substructure and porcelain.

\section{Materials and Methods}

A total of 180 disc-shaped metal samples with a diameter of $1 \mathrm{~cm}$ and a thickness of $3 \mathrm{~mm}$ were produced. The samples were divided into six groups (n $=15$ ) according to the technique used to produce the metal substructures-casting, milling, and SLS-and the chemical composition of the metal substructure- $\mathrm{Co}-\mathrm{Cr}$ and $\mathrm{Ti}$. The materials used are shown in Table 1.

\section{Production of metal substructures}

To standardize the metal substructures, the sample discs were designed using a CAD program (Procera; Nobel Biocare Ltd., Switzerland). For the Ti and $\mathrm{Co}-\mathrm{Cr}$ groups to be produced by casting, the CAD design was transferred to a CAM unit, and duplicate models were obtained by milling from a prefabricated temporary acrylic block (Telio CAD; Ivoclar Vivadent, Liechtenstein). Duplicate models were fixed to an annular silicon and embedded in the refractory investment. A phosphate-bonded sensitive investment material (Rematitan Plus Speed; Dentaurum, Germany) and vacuum-pressure casting (Autocast Universal $₫$ 230; Dentaurum, Germany) were used to cast the $\mathrm{Ti}$ samples. To cast the $\mathrm{Co}-\mathrm{Cr}$ samples, a conventional phosphate-bonded investment material (Ceramvest $\mathrm{Hi}$ Speed; Protechno, Spain) was mixed with distilled water in a vacuum mixing device (MultiVac 4; Degussa, Germany) for $45 \mathrm{~s}$ according to the manufacturer's instructions. The samples were cast with a $\mathrm{Co}-\mathrm{Cr}$ alloy (Microlit ISI; Schütz Dental, Germany) placed in the 
casting chamber of an induction furnace (Nautilus CC Plus; Bego, Germany). Since the CAD program used to design the samples to be produced by milling is a closed system and allows the production of a maximum of three members at a time, the previously obtained temporary acrylic block duplicate discs were scanned again (DWOS; Dental Wings 3D Scan, Canada) using a laboratory-type CAM program (Yenadent CAM 4.0, DWOS; Dental Wings, Canada).

Table 1. Materials used in the study and their technical features

\begin{tabular}{|c|c|c|c|}
\hline Metal Alloy & Type & Fabrication Method & Weight Composition (\%) \\
\hline Microlit ISI & $\begin{array}{l}\text { Co- } \mathrm{Cr} \\
\text { Type } 3\end{array}$ & Casting & $\begin{array}{c}\% 61.1 \text { Cobalt, \%27.8 Chromium, \%8.5 } \\
\text { Tungsten, \%1.7 Silicon }\end{array}$ \\
\hline Copra Bond K & $\begin{array}{l}\text { Co-Cr } \\
\text { Type } 4\end{array}$ & Milling & $\begin{array}{c}\text { \%61 Cobalt, \%28 Chromium, \%8.5 } \\
\text { Tungsten, \%1.65 Silicon }\end{array}$ \\
\hline EOS CobaltChrome SP2 & $\begin{array}{l}\text { Co-Cr } \\
\text { Type } 4\end{array}$ & Selective Laser Sintering & $\begin{array}{c}\% 61.8 \text { Cobalt, \%25.7 Chromium, \%5.9 } \\
\text { Tungsten, \%1.2 Silicon }\end{array}$ \\
\hline Tritan & $\begin{array}{c}\mathrm{Ti} \\
\text { Grade } 1\end{array}$ & Casting & $\begin{array}{c}\text { \%99,5 Titanium, Iron, Oxygen, } \\
\text { Hydrogen, Nitrogen, Carbon }\end{array}$ \\
\hline CopraTi 2 & $\begin{array}{c}\mathrm{Ti} \\
\text { Grade } 2\end{array}$ & Milling & $\begin{array}{c}\text { \%99,5 Titanium, Oxygen, Hydrogen, } \\
\text { Nitrogen, Carbon }\end{array}$ \\
\hline Rematitan $C L$ & $\begin{array}{c}\mathrm{Ti} \\
\text { Grade } 4\end{array}$ & Selective Laser Sintering & $\begin{array}{c}\text { \%90 Titanium, \%6 Aliminium, \%4 } \\
\text { Vanadium, Oxygen, Hydrogen, } \\
\text { Nitrogen, Carbon }\end{array}$ \\
\hline
\end{tabular}

Thus, the positions of the samples to be milled in the disc were determined. This process was followed by the insertion of both $\mathrm{Ti}$ and $\mathrm{Co}-\mathrm{Cr}$ discs into a milling device (Fedi18; Mariotti, Italy) and the fabrication of the metal substructures. The CAD data of the samples to be produced by SLS were transferred to the Laser Power Monitoring (DWOS; Dental Wings, Canada) program. Alloy powder (EOS CobaltChrome SP2, Munich, Germany) for the production of $\mathrm{Cr}$-Co samples was placed in the powder bed of a laser sintering device (EOSINT M 270, Munich, Germany) and exposed to 400W irradiation with a Yb-fiber laser tip. Cr-Co samples were obtained by forming $50-\mu \mathrm{m}$ layers in each irradiation. Then, following the manufacturer's instructions, to reduce the stresses in the metal and ensure metal stability, the samples were subjected to final firing in a heating furnace (Programat EP 3000, Ivoclar Vivadent, Lihtenstein) at $750^{\circ} \mathrm{C}$ for $4.5 \mathrm{~h}$ and then allowed to cool down to room temperature. To produce $\mathrm{Ti}$ samples, $\mathrm{Ti}$ powder (Rematitan $\mathrm{Cl}$; Dentaurum, Germany) was placed in the powder bed of a laser sintering device (Concept Laser M2; General Electric, Germany), and 200-W irradiation was performed with a Yb-fiber laser tip. Care was taken to create $50-\mu \mathrm{m}$ layers in each irradiation. The produced samples were subjected to finishing firing in a heating furnace at $750^{\circ} \mathrm{C}$ for $4.5 \mathrm{~h}$ and then left to cool down to room temperature. Before the surface analysis and porcelain application, all samples were sandblasted with 110- $\mu \mathrm{m}$ aluminum oxide powder (Korox; Bego, Germany) under 2-bar pressure, at a $45^{\circ}$ angle, and from a $2-\mathrm{cm}$ distance for $10 \mathrm{~s}$. Then, the thickness of the samples was checked using a digital caliper (Absolute Digimatic Caliper Series 551; Mituyoto, Japan).

\section{Determination of the surface characteristics of the substructures}

Ninety randomly selected samples from each group were allocated to measure the surface roughness and calculate the oxide layer thickness. After cleaning the sample surfaces with steam, the roughness averages (Ra) were calculated with a contact-type profilometer (Surftest SJ-301; Mitutoyo, Japan), which was 
calibrated before each measurement. Three measurements of $3 \mathrm{~mm}$ in length were taken from the samples, and the average of the obtained values was calculated. Before oxide layer thickness measurements, the samples were subjected to an oxidation layer heating cycle according to the manufacturer's instructions (Table 2). The specimens were divided vertically into two parts using a precision metal-cutting device (Metacut 250; Metkon, Turkey), and the cross-sectional surfaces were sanded with 240 , $400,600,800,1000$, and 1200 grit abrasives in an automatic sanding machine. The samples were then cleaned with distilled water in an ultrasonic cleaner.
Next, a nondestructive energy-dispersive X-ray (EDAX) test was performed to analyze their chemical composition. Samples were mounted on aluminum studs and surface-coated with gold and palladium using a spray-coating device (Polaron SC7620 Sputter Coater; VG Microtech, England). Scanning electron microscope (SEM; Quanta FEG 250; FEI, USA) images were obtained. EDAX elemental analysis was performed to ensure that the layer displayed in contrast was the oxide layer, and the average oxide layer thickness was calculated from three measurements of the relevant layer (Figures 1$6)$.

Table 2. Oxidation layer heating cycle of the metals

\begin{tabular}{ccccccccc} 
& Drying & Low & High & Temperature & Vacuum & Initial & Reduced & Vacuum \\
Metal & $\begin{array}{c}\text { Time } \\
(\mathrm{min})\end{array}$ & $\begin{array}{c}\text { Temperature } \\
\left({ }^{\circ} \mathrm{C}\right)\end{array}$ & $\begin{array}{c}\text { Temperature } \\
\left({ }^{\circ} \mathrm{C}\right)\end{array}$ & $\begin{array}{c}\text { Rise } \\
(\mathrm{oC} / \mathrm{min})\end{array}$ & $\begin{array}{c}\text { Level } \\
(\mathrm{cm} / \mathrm{Hg})\end{array}$ & $\begin{array}{c}\text { Vacuum } \\
\left({ }^{\circ} \mathrm{C}\right)\end{array}$ & $\begin{array}{c}\text { Vacuum } \\
\left({ }^{\circ} \mathrm{C}\right)\end{array}$ & $\begin{array}{c}\text { Time } \\
(\mathrm{min})\end{array}$ \\
\hline $\mathrm{Ti}$ & 3 & 500 & 800 & 50 & 74 & 500 & 790 & 3 \\
$\mathrm{Co}-\mathrm{Cr}$ & 6 & 403 & 1100 & 60 & 74 & 550 & 770 & 6
\end{tabular}

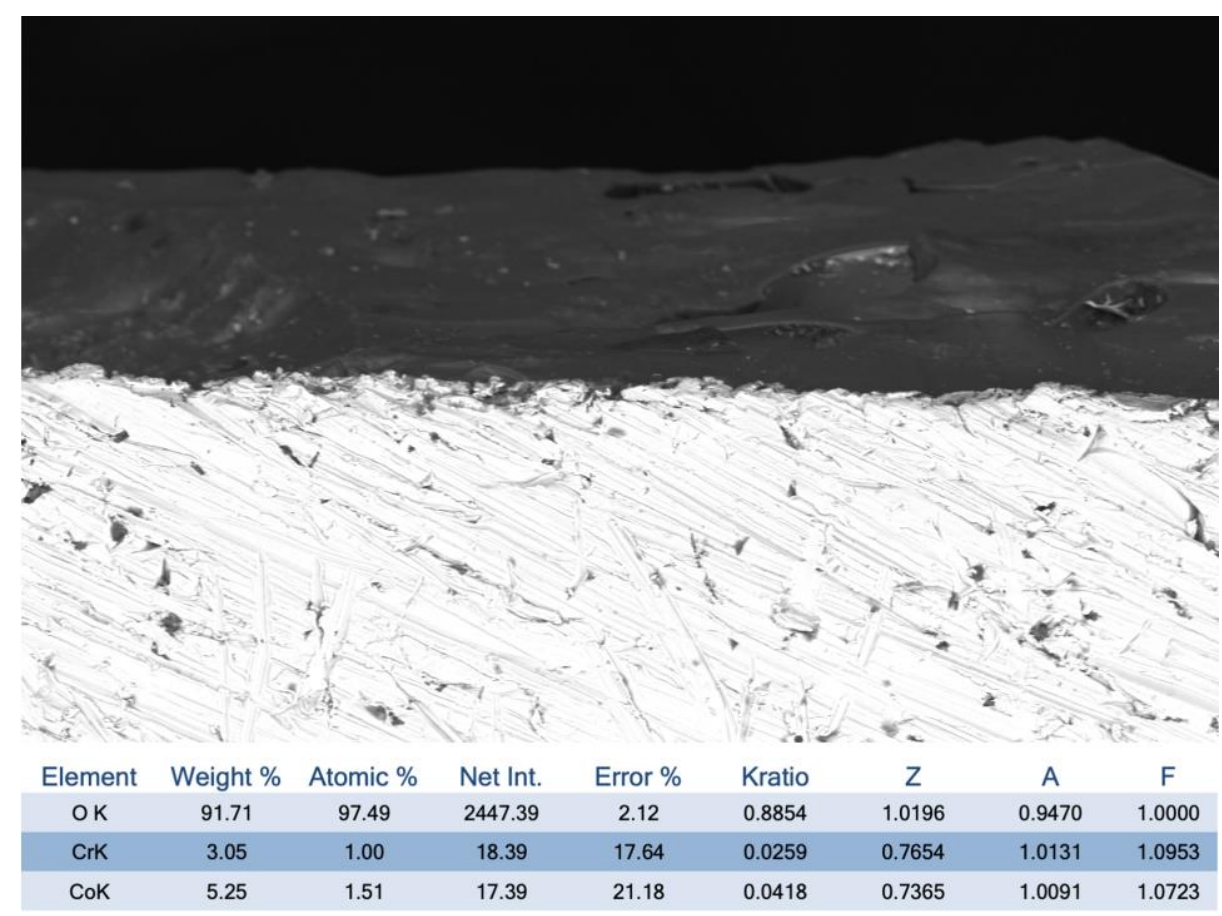

Figure 1. SEM image and EDAX analysis of $\mathrm{Co}-\mathrm{Cr}$ substructure produced by casting 


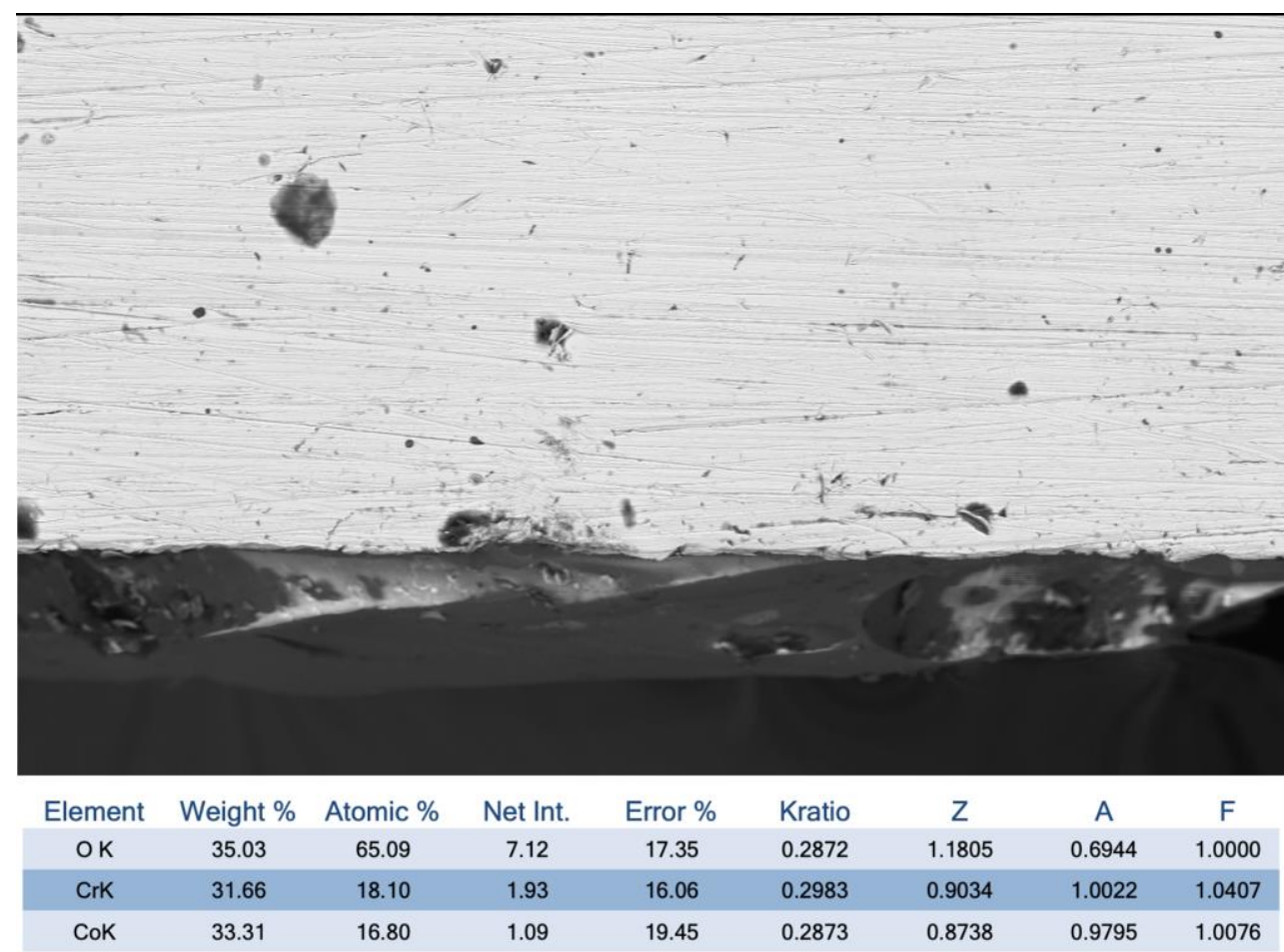

Figure 2. SEM image and EDAX analysis of $\mathrm{Co}-\mathrm{Cr}$ substructure produced by milling

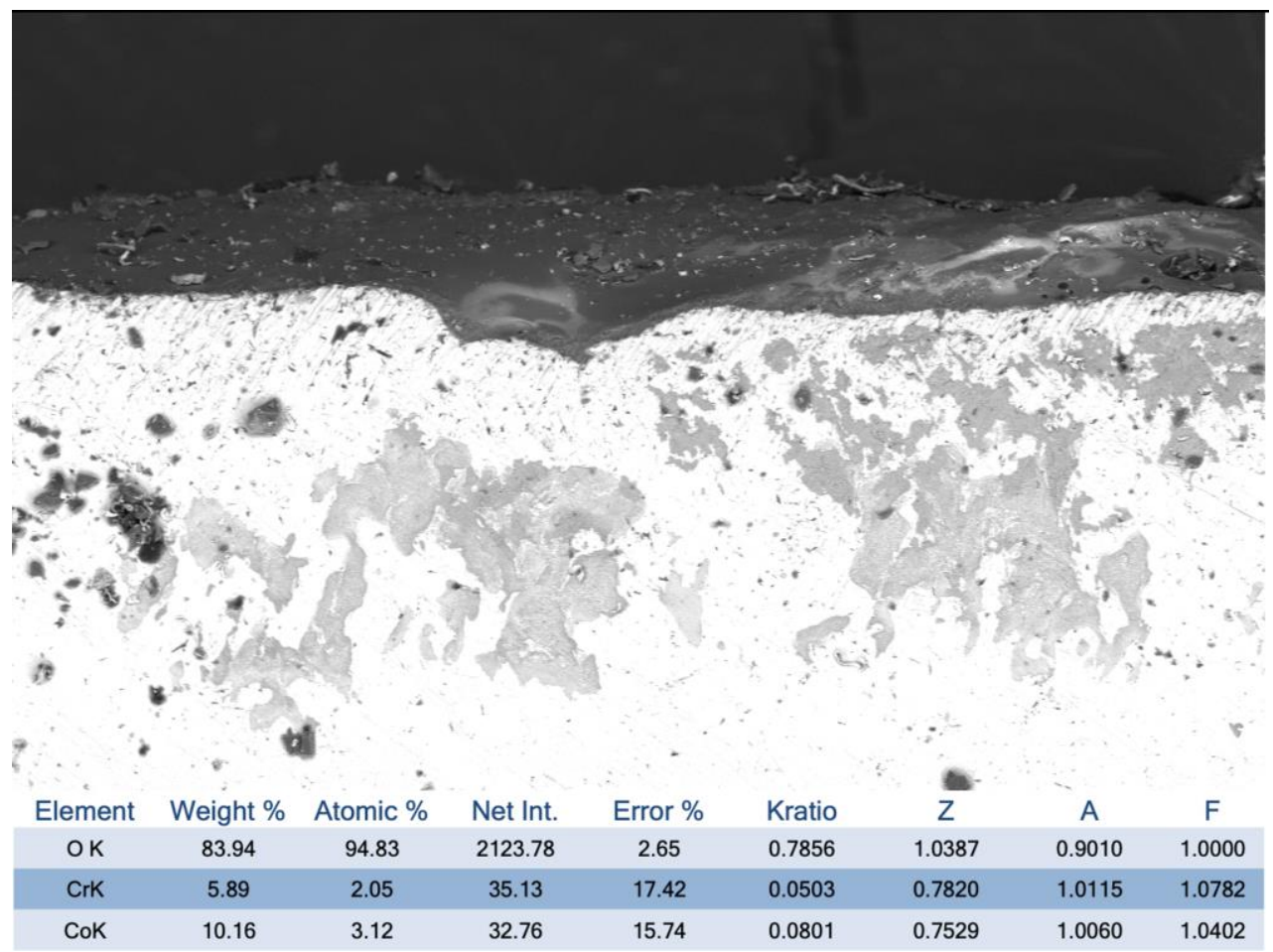

Figure 3. SEM image and EDAX analysis of Co-Cr substructure produced by SLS 


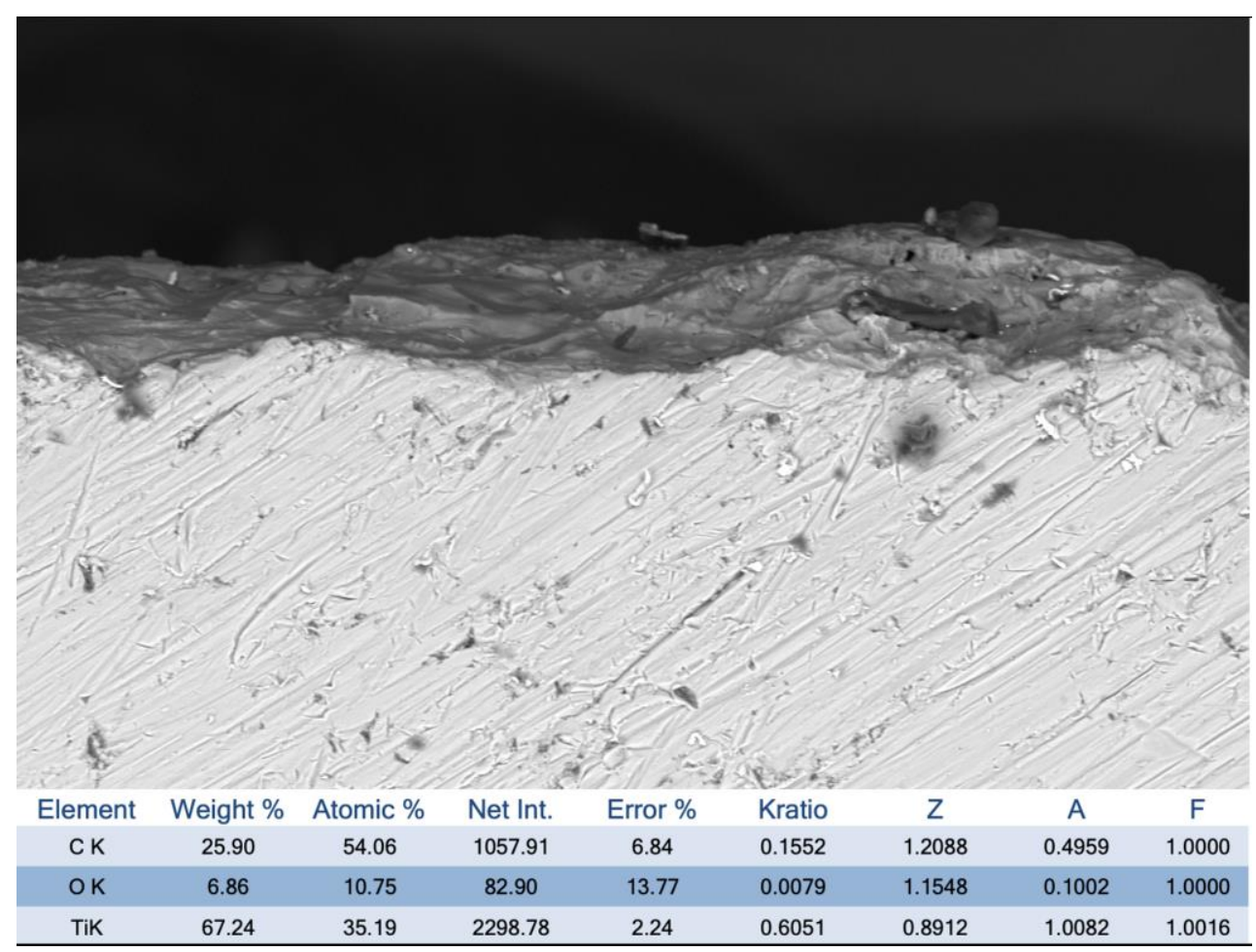

Figure 4. SEM image and EDAX analysis of Ti substructure produced by casting

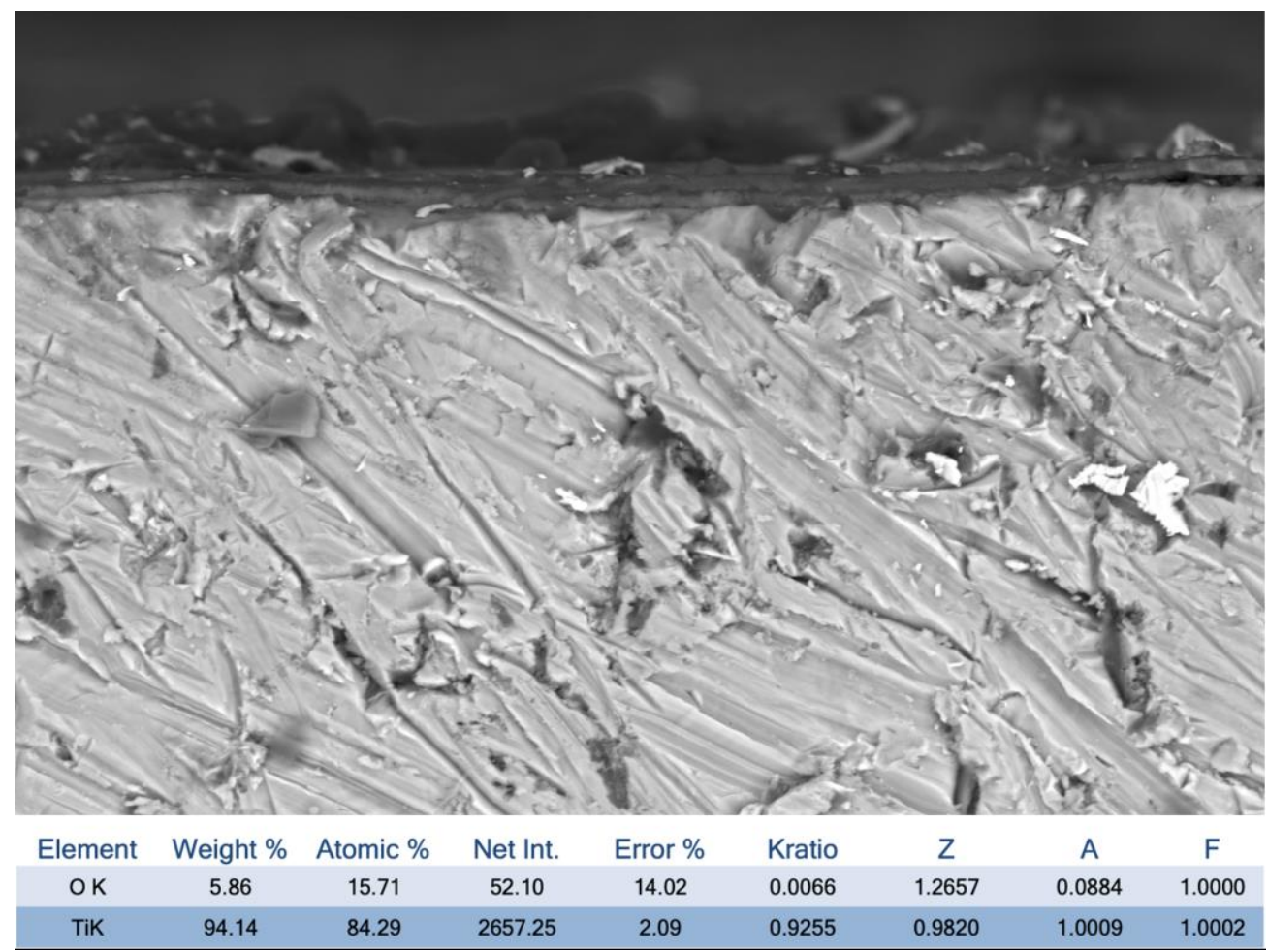

Figure 5. SEM image and EDAX analysis of Ti substructure produced by milling 


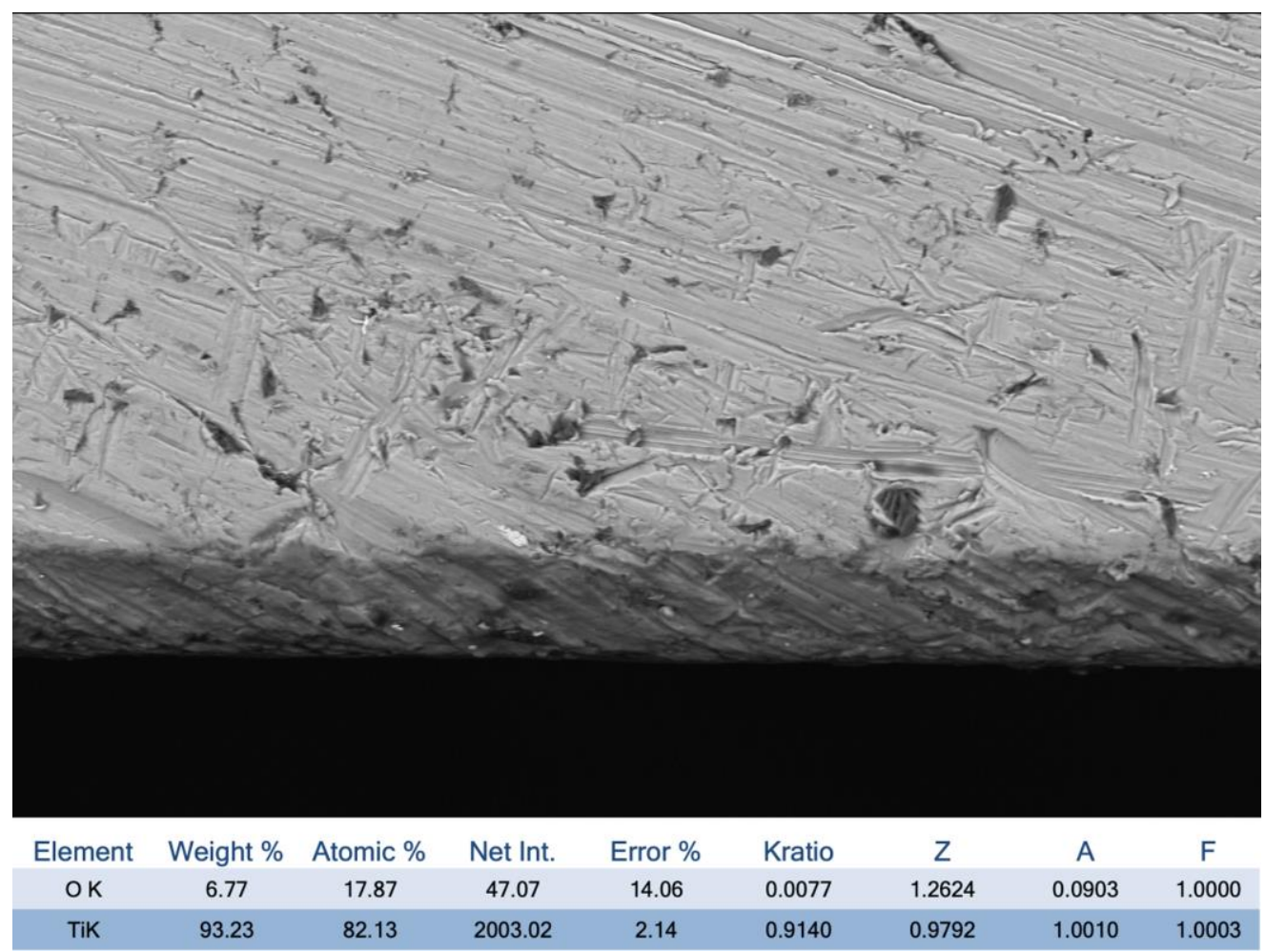

Figure 6. SEM image and EDAX analysis of Ti substructure produced by SLS

\section{Veneering porcelain application}

Ninety samples to be used for metal-ceramic shear bond strength testing were reserved for veneering porcelain application. To standardize the dimensions of the veneering porcelain, a special detachable stainlesssteel mold was designed. Specimens were placed in this mold, and veneered porcelain was applied using a manual layering technique according to the manufacturer's instructions: opaque body porcelain layers (Table 3). Then, the porcelain parts of the samples were measured with a digital caliper, considering the firing shrinkage, and care was taken to obtain a thickness of $4 \mathrm{~mm}$.

Table 3. Firing schedules of the veneering porcelains according to manufacturers' instructions

\begin{tabular}{|c|c|c|c|c|c|c|}
\hline Porcelain & & $\begin{array}{c}\text { Temperature } \\
\left({ }^{\circ} \mathrm{C}\right)\end{array}$ & $\begin{array}{l}\text { Time } \\
\text { (min) }\end{array}$ & $\begin{array}{l}\text { Heating rate } \\
\qquad\left({ }^{\circ} \mathrm{C} / \mathrm{min}\right)\end{array}$ & $\begin{array}{c}\text { Firing } \\
\text { Temperature } \\
\left({ }^{\circ} \mathrm{C}\right)\end{array}$ & $\begin{array}{c}\text { Holding } \\
\text { Time } \\
\text { (min) }\end{array}$ \\
\hline & Opaque & 400 & 2 & 98 & 790 & 1 \\
\hline Titankeramik & $\begin{array}{c}\text { Body } \\
\text { Porcelain }\end{array}$ & 400 & 6 & 53 & 770 & 1 \\
\hline & Opaque & 500 & 8 & 65 & 980 & 1 \\
\hline $\begin{array}{l}\text { Super Porcelain } \\
\text { Ex-3 Press }\end{array}$ & $\begin{array}{c}\text { Body } \\
\text { Porcelain }\end{array}$ & 600 & 10 & 45 & 935 & 0 \\
\hline
\end{tabular}




\section{Shear bond strength test and surface fracture analysis}

At the end of the process, the samples were embedded in acrylic resin (SC Cold Acrylic; Imicryl, Turkey) and fixed on a universal testing device (Autograph AGS-X Series; Shimadzu Corp., Japan) with the porcelain-metal substructure interface at the center. Using a blade-shaped indenter at a speed of 1 $\mathrm{mm} / \mathrm{min}$, force was applied until fracturing occurred, and the final force was recorded in newtons. The shear bond strength was converted to megapascals $(\mathrm{MPa})$ by dividing the ultimate force by the bonding area. Using these data, the mean and standard deviation of the failure load in each group was calculated. Posttest surfaces were examined under a stereomicroscope (SZX-ILLB100; Olympus Optical, Japan) at 10x magnification. The failure modes were classified as cohesive failure within veneer porcelain, adhesive failure between the metal substructure and porcelain and their combination.

\section{Statistical analysis}

Data normality was assessed using the Shapiro-Wilk test. Two-way multivariate analysis of variance (MANOVA) was used to compare oxide layer thickness, surface roughness, and shear bond strength according to the metal and production technique, and Tukey's honestly significant difference (HSD) test was used for multiple comparisons of the main effects. Multiple interaction comparisons were performed using one-way ANOVA, and multiple comparisons were performed using Tamhane's T2 and Tukey's HSD tests. The chisquare test was used to compare failure types according to the metal and production techniques. Pearson's correlation coefficient was used to examine the relationships between shear bond strength, oxide layer thickness, and surface roughness. The results were presented as means \pm standard deviations for quantitative data and as frequencies (percentages) for categorical data. The significance level was set to $p<$ 0.05 .

\section{Results}

The $\mathrm{Ra}$ values obtained in each group after sandblasting are shown in Table 4. Two-way MANOVA revealed that the metal and technique used in the substructure production had significant effects on surface roughness $(p<0.001)$. However, the partial eta squared values showed that the production technique had the strongest effect on surface roughness. The Co$\mathrm{Cr}$ group produced by SLS had the highest mean Ra value $(5.5 \mu \mathrm{m})$, while the Ti group produced by SLS had the lowest value $(0.5 \mu \mathrm{m})$. However, it is quite remarkable that low surface roughness values were observed in the milling groups, regardless of the metal used.

Table 4. Descriptive statistics of oxide layer, surface roughness and shear bond strength values according to metal and fabrication method

\begin{tabular}{|c|c|c|c|c|}
\hline & \multirow{2}{*}{ Fabrication Method } & \multicolumn{2}{|c|}{ Metal } & \multirow{2}{*}{ Total } \\
\hline & & $\mathrm{Co}-\mathrm{Cr}$ & $\mathrm{Ti}$ & \\
\hline \multirow{4}{*}{ Oxide Layer Thickness } & Casting & $3,6 \pm 0,2 D$ & $18,1 \pm 0,3 \mathrm{~B}$ & $10,8 \pm 7,4 a$ \\
\hline & Milling & $5,5 \pm 0,3 \mathrm{C}$ & $18,6 \pm 0,2 \mathrm{~A}$ & $12,0 \pm 6,7 b$ \\
\hline & Selective Laser Sintering & $5,3 \pm 0,1 C$ & $18,6 \pm 0,2 \mathrm{~A}$ & $12,0 \pm 6,8 b$ \\
\hline & Total & $4,8 \pm 0,9$ & $18,4 \pm 0,3$ & $11,6 \pm 6,9$ \\
\hline \multirow{4}{*}{ Surface Roughness } & Casting & $3,4 \pm 0,2 B$ & $3,1 \pm 0,4 \mathrm{~B}$ & $3,3 \pm 0,4 a$ \\
\hline & Milling & $0,8 \pm 0,2 \mathrm{D}$ & $0,6 \pm 0,2 \mathrm{~A}$ & $0,7 \pm 0,2 b$ \\
\hline & Selective Laser Sintering & $5,5 \pm 0,3 C$ & $0,5 \pm 0,1 \mathrm{~A}$ & $3,0 \pm 2,5 c$ \\
\hline & Total & $3,2 \pm 2,0$ & $1,4 \pm 1,3$ & $2,3 \pm 1,9$ \\
\hline \multirow{4}{*}{ Shear Bond Strength } & Casting & $53,8 \pm 1,4 \mathrm{~A}$ & $32,2 \pm 1,1 \mathrm{D}$ & $43,0 \pm 11,0 a$ \\
\hline & Milling & $49,5 \pm 1,1 \mathrm{~B}$ & $44,2 \pm 1,0 \mathrm{E}$ & $46,9 \pm 2,9 b$ \\
\hline & Selective Laser Sintering & $51,1 \pm 1,2 \mathrm{C}$ & $41,7 \pm 0,7 \mathrm{~F}$ & $46,4 \pm 4,9 b$ \\
\hline & Total & $51,5 \pm 2,2$ & $39,4 \pm 5,3$ & $45,4 \pm 7,3$ \\
\hline
\end{tabular}


Measurements obtained from the samples subjected to oxidation heat treatment showed significantly thicker oxide layers in the $\mathrm{Ti}$ groups produced by milling and SLS ( $p<0.001)$. The partial eta squared values showed that the metal factor had the strongest effect on oxide layer thickness, whereas the metal-production technique interaction had the weakest effect. The Co$\mathrm{Cr}$ group produced by casting had the thinnest oxide layers (3.6 nm; Table 4). The average oxide layer thickness of all Ti groups was $18.4 \mathrm{~nm}$, whereas that of the $\mathrm{Co}-\mathrm{Cr}$ groups was $4.8 \mathrm{~nm}$. Moreover, SEM analysis showed that the $\mathrm{Ti}$ samples had more irregular oxide layers with heterogeneous thicknesses (Figures 4-6).

The interaction between metal, production technique, and metal-production technique had a significant effect on shear bond strength $(p<0.001)$. The highest mean value $(53.8 \mathrm{MPa})$ was observed in the $\mathrm{Co}-\mathrm{Cr}$ group produced by casting, while the lowest value $(32.2 \mathrm{MPa})$ was obtained in the Ti group produced by casting. Pearson's correlation coefficient revealed a weak but statistically significant positive relationship between shear bond strength and oxide layer thickness $(r=0.236 ; p<0.025)$ and a statistically significant negative relationship between surface roughness and shear bond strength $(r=-0.834 ; p<0.001)$.

Both the metal and the production technique had significant effects on the failure type $(p=0.043$ and $p$ $=0.027$, respectively). Mixed failure was observed in $71.1 \%$ of the samples in the Co-Cr groups and $48.9 \%$ of the samples in the $\mathrm{Ti}$ groups, whereas adhesive failure was observed in $26.7 \%$ of the samples in the $\mathrm{Co}-\mathrm{Cr}$ groups and $5.1 \%$ of the samples in the Ti groups.

\section{Discussion}

The bond strength at the metal-ceramic interface depends on the chemical bond, micromechanical interlock, linear thermal expansion coefficients, and production technique of the metal substructures (18). The primary aim of this study was to evaluate the surface characteristics of $\mathrm{Ti}$ and $\mathrm{Co}-\mathrm{Cr}$ substructures produced using three methods and the metal substructure-porcelain bond strength. The results showed that the surface characteristics, including surface roughness, oxide layer, and bond strength with porcelain, differed significantly depending on the metal and production technique used and the interaction between these two factors. Consequently, the null hypothesis was rejected.

Incompatibilities between materials' thermal expansion coefficients play an essential role in connection failures between the metal substructure and the veneering porcelain (3). Guilherme et al., who evaluated the fatigue performance of pure $\mathrm{Ti}$ and $\mathrm{Ti}$ alloys, found that this mismatch was the main cause of cervical porcelain fracture, which is frequently observed in PFMs (19). Similarly, Lopes et al. reported that porcelain delamination may occur on the metal surface when the thermal expansion coefficient difference between the metal and porcelain is more than $1 \times 10-6 \mathrm{~K}-1$ (20). In light of these findings, in this study, two types of veneering porcelain exhibiting optimal thermal expansion coefficient compatibility with the substructure materials were used, and Titankeramik (VITA Zahnfabrik, Germany), a low-fusing porcelain, was preferred as the veneering ceramic for $\mathrm{Ti}$ substructures. To increase the bond strength between metal substructures and porcelain, various surface treatments are recommended, including sandblasting, silanization of the surface with Rocatec, bonding, nitridation, and hydrochloric acid application (12). Although studies have shown bonding and sandblasting to be prominent among these applications (21), another study reported that bond film thickness and operator experience during bond application may also affect the connection in the opposite direction (8). In a study comparing the effectiveness of bonding agent application and sandblasting on $\mathrm{Ti}$ substructures produced using two different methods, Antanasova et al. found that sandblasting created the optimal surface for porcelain wettability; however, they noted that a particle size that would not contaminate the metal surface should be preferred (14). For this reason, in our study, metal surfaces were sandblasted with $110-\mu \mathrm{m}$ aluminum oxide powder before porcelain application to prevent variations related to the surface treatment and application method.

Many mechanical strength tests can be used to evaluate the clinical performance of PFMs, the focus of which is the bond between the veneering porcelain and the metal substructure. Among them, shear bond strength testing is prominent in terms of ease of application, simplicity of sample preparation and test procedure, and rapid obtainment of results (9). However, all laboratory tests are susceptible to several variations and require standardization to accurately reflect the clinical situation. In this study, ISO 29022:2013 standards were followed to increase the reliability of the results (22).

In a pioneering work evaluating the bond strength between cast $\mathrm{Ti}$ and veneering porcelain, Papadopoulos et al. showed that surface roughness plays a key role because it increases the surface area, mechanical locking, and wettability (23). Another study comparing the surface roughness of $\mathrm{Ti}$ and $\mathrm{Co}-\mathrm{Cr}$ samples produced using three different techniques found that the metal used significantly affected the surface roughness, whereas the production technique did not have the same statistical significance. The highest roughness values were observed in $\mathrm{Ti}$ samples, among which samples produced by selective laser melting (SLM) had the greatest roughness (3). In our study, the metal used in a similar way had a significant effect on surface roughness. However, higher roughness values were observed in the Co- $\mathrm{Cr}$ groups. This may be because the metal compositions used in the production of the samples were not identical and the surface treatments applied after production were different. Another difference between the two studies is the significant effect of the production technique on the surface roughness observed in our study. In line with this finding, Antanasova et al. reported that the production technique had a significant effect on the surface 
roughness of $\mathrm{Ti}$ samples produced with different techniques and that the samples produced by SLM showed the highest roughness (14).

Researchers agree that metal oxides play a major role in chemical bonds. However, a recent study demonstrated that the thickness of the oxide layer is also important in chemical bonding and that the bond strength may weaken if the thickness increases (24). Adachi et al. showed that porcelain is easily delaminated from the metal surface in the presence of a thick oxide layer (25). A study showed evaluating the bond strength between $\mathrm{Ti}$ and $\mathrm{Co}-\mathrm{Cr}$ substructures and veneering porcelain have shown that high temperatures result in the formation of thick hard layers on $\mathrm{Ti}$ surfaces, which reduces ductility and fatigue resistance (26). Another study evaluating the oxide layer thickness of metal substructures using the AES depth profiling method detected layers thicker than $300 \mathrm{~nm}$ on $\mathrm{Ti}$ surfaces, noting, however, that the thickness varied depending on the production technique, with digitally produced samples being thinner and more homogeneous (3). In our study, the Ti groups exhibited thicker oxide layers than the $\mathrm{Co}-\mathrm{Cr}$ groups, with the production technique significantly affecting the layer thickness. Moreover, the oxide layer thickness was greater than in Antanasova et al.'s study. This may be because in our study, the measurements were made directly on the metal surface exposed to the oxidation thermal cycle and were performed using SEM, whereas Antanasova et al.'s study, the measurements were made on the porcelain-metal complex, which may have caused loss of EDS signals due to thickness.

The effects of production methods on the bond strength of metal substructures with porcelain have become a hot topic in the literature. However, few studies have evaluated the combined effects of $\mathrm{Ti}$ and $\mathrm{Co}-\mathrm{Cr}$ substructures and production techniques (2). However, not only the metal type but also small changes in the chemical composition of the metal, such as the size of atoms, the lattice structures of metal components, and the values and reactivity of particles, can play a vital role in bond strength (27). Therefore, it is particularly important to understand the effects of both the production method and the metals on bond strength to provide guidance to clinicians. In this study, both the production technique and the metal used had a significant effect on shear bond strength. The strength in the $\mathrm{Co}-\mathrm{Cr}$ groups was significantly greater than in the Ti groups. To the authors' knowledge, only one previous study has compared the porcelain bond strength of $\mathrm{Ti}$ and $\mathrm{Co}-\mathrm{Cr}$ alloys. That study also obtained higher values in the Co- $\mathrm{Cr}$ groups and found that the efficiency of the production technique varied depending on the metal but that the production technique had a significant effect on $\mathrm{Ti}$ but not $\mathrm{Co}-\mathrm{Cr}$ substructures (3). Conversely, a meta-analysis evaluating the effects of production techniques on porcelain bond strength in $\mathrm{Co}-\mathrm{Cr}$ substructures found that bond strength ranges from 16.52 to $51.23 \mathrm{MPa}$ depending on the production technique and that the production technique has an undeniable effect (2).
These conflicting findings may be due to many differences, including the porcelain application procedure and parameters such as the layer thickness used in additive technology, the processes following the production of the metal, and the number of porcelain layers applied. A study evaluating the effects of production techniques on the bond strength between $\mathrm{Ti}$ and porcelain found that SLM, an additive technology, achieved greater bond strength than casting and milling techniques (9). Conversely, another study comparing the effects of SLM and milling on Tiporcelain bond strength found no significant difference between the fabrication techniques (14). In our study, the group of $\mathrm{Ti}$ produced by milling had the highest bond strength, while the $\mathrm{Ti}$ group produced by casting had the lowest. In line with our findings, Antanasova et al. also observed the highest bond strength in $\mathrm{Ti}$ produced by milling (3). According to ISO 9693:2019 standards, the lowest bond strength value for metalceramic systems is $25 \mathrm{MPa}(28)$. It is noteworthy that in our study, no group had a lower value.

This study has certain limitations. In additive methods, the mechanical and fractographic properties of the fused parts may differ depending on the laser application of different devices (1). In our study, a single device and a single laser parameter were chosen for the SLS method, and the effects of different devices were not evaluated. A previous study also showed that the bond strength differs significantly depending on the porcelain used (9). However, in our study, the effects of veneering porcelain on bond strength were not investigated. Furthermore, EDAX elemental analysis was used only to confirm the determination of the oxide layer, and the effects of the elemental distribution in the oxide layer on bond strength were not evaluated.

\section{Conclusions}

Within the limitations of this study, the following conclusions can be drawn:

1. The surface roughness of metal substructures was affected by both the metal and the production technique. Among the $\mathrm{Co}-\mathrm{Cr}$ groups, those produced by SLS had the highest roughness, while among the $\mathrm{Ti}$ groups, those produced by casting showed the greatest roughness.

2. The Ti groups, which are known to be highly reactive at high temperatures, had more irregular and thicker oxide layers than the $\mathrm{Co}-\mathrm{Cr}$ groups.

3. The metal used in PFMs and the production technique had a statistically significant effect on porcelain bond strength. The $\mathrm{Co}-\mathrm{Cr}$ substructureveneering porcelain shear bond strength was higher than the $\mathrm{Ti}$ substructure--veneering porcelain bond strength. However, it should be kept in mind that there is no ideal production technique and that the effects of the production technique differ depending on the metal used. 
Acknowledgments: This research was partially presented in FDI World Dental Federation Congress 2017 in Madrid. The authors sincerely thank Dr. Naci Murat for his support regarding statistical analysis.

\section{Peer-review: Externally peer-reviewed.}

Author Contributions: Conception - B.Ü.D.; Design - N.M.E., B.Ü.D.; Supervision - N.M.E.; Materials - B.Ü.D., N.M.E.; Data Collection and/or Processing - B.Ü.D., N.M.E.; Analysis and/or Interpretation B.Ü.D.; Literature Review - N.M.E., B.Ü.D.; Writer - N.M.E.; B.Ü.D.; Critical Review -N.M.E.

Conflict of Interest: No conflict of interest was declared by the authors.

Financial Disclosure: This research was financially supported by Van Yüzüncü Yll University, Scientific Research Project Division (2014SBE-D020).

\section{References}

1. Yoldan EE, Türker N, Büyükkaplan UȘ, Özarslan $M M$, Karalı $R$ and Deniz AT. Evaluation of the Bond Strengths between Dental Porcelain and Cobalt-Chromium Metal Frameworks Manufactured with Different Techniques after the Thermal Aging Process. Scanning 2020;2020:9315236. (Crossref)

2. Revilla-León $M$, Gómez-Polo $M$, Park SH, Barmak AB and Özcan $M$. Adhesion of veneering porcelain to cobalt-chromium dental alloys processed with casting, milling, and additive manufacturing methods: A systematic review and metaanalysis. J Prosthet Dent 2021. (Crossref)

3. Antanasova M, Kocjan A, Kovač J, Žužek B and Jevnikar P. Influence of thermo-mechanical cycling on porcelain bonding to cobalt-chromium and titanium dental alloys fabricated by casting, milling, and selective laser melting. J Prosthodont Res 2018;62(2):184-94. (Crossref)

4. Akova T, Ucar Y, Tukay A, Balkaya MC and Brantley WA. Comparison of the bond strength of laser-sintered and cast base metal dental alloys to porcelain. Dent Mater 2008;24(10):1400-4. (Crossref)

5. Dimitriadis K, Papadopoulos T and Agathopoulos S. Effect of Bonding Agent on Metal-Ceramic Bond Strength between Co$\mathrm{Cr}$ Fabricated with Selective Laser Melting and Dental Feldspathic Porcelain. J Prosthodont 2019;28(9):1029-36. (Crossref)

6. Grimaudo NJ. Biocompatibility of nickel and cobalt dental alloys. Gen. Dent. 2001;49(5):498-503; quiz 4-5.

7. Buciumeanu M, Bagheri A, Souza JCM, Silva FS and Henriques B. Tribocorrosion behavior of hot pressed CoCrMo alloys in artificial saliva. Tribol. Int. 2016;97:423-30. (Crossref)

8. Al Hussaini I and Al Wazzan KA. Effect of surface treatment on bond strength of low-fusing porcelain to commercially pure titanium. J Prosthet Dent 2005;94(4):350-6. (Crossref)

9. Iseri U, Ozkurt Z and Kazazoglu E. Shear bond strengths of veneering porcelain to cast, machined and laser-sintered titanium. Dent Mater J 2011;30(3):274-80. (Crossref)

10. Papia E, Arnoldsson P, Baudinova A, Jimbo R and Vult VONSP. Cast, milled and EBM-manufactured titanium, differences in porcelain shear bond strength. Dent Mater J 2018;37(2):21421. (Crossref)
11. Elsaka SE. Influence of surface treatments on adhesion of porcelain to titanium. J Prosthodont 2013;22(6):465-71. (Crossref)

12. Haag $P$ and Nilner $K$. Bonding between titanium and dental porcelain: a systematic review. Acta Odontol Scand 2010;68(3):154-64. (Crossref)

13. Cai Z, Bunce N, Nunn ME and Okabe T. Porcelain adherence to dental cast CP titanium: effects of surface modifications. Biomaterials 2001;22(9):979-86. (Crossref)

14. Antanasova $M$, Kocjan $A$, Hočevar $M$ and Jevnikar P. Influence of surface airborne-particle abrasion and bonding agent application on porcelain bonding to titanium dental alloys fabricated by milling and by selective laser melting. J Prosthet Dent 2020;123(3):491-9. (Crossref)

15. Al Jabbari $Y S$, Koutsoukis $T$, Barmpagadaki $X$ and Zinelis $S$. Metallurgical and interfacial characterization of PFM Co- $\mathrm{Cr}$ dental alloys fabricated via casting, milling or selective laser melting. Dent Mater 2014;30(4):e79-88. (Crossref)

16. Qian B, Saeidi K, Kvetková L, Lofaj F, Xiao C and Shen Z. Defects-tolerant $\mathrm{Co}-\mathrm{Cr}$-Mo dental alloys prepared by selective laser melting. Dent Mater 2015;31(12):1435-44. (Crossref)

17. Bae E-J, Kim J-H, Kim W-C and Kim H-Y. Bond and fracture strength of metal-ceramic restorations formed by selective laser sintering. J Adv Prosthodont 2014;6(4):266-71. (Crossref)

18. Li KC, Tran L, Prior DJ, Waddell JN and Swain MV. Porcelain bonding to novel $\mathrm{Co}-\mathrm{Cr}$ alloys: Influence of interfacial reactions on phase stability, plasticity and adhesion. Dent Mater 2016;32(12):1504-12. (Crossref)

19. Guilherme AS, Henriques GE, Zavanelli RA and Mesquita MF. Surface roughness and fatigue performance of commercially pure titanium and Ti-6Al-4V alloy after different polishing protocols. J Prosthet Dent 2005;93(4):378-85. (Crossref)

20. Lopes SC, Pagnano VO, Rollo JMDdA, Leal MB and Bezzon OL. Correlation between metal-ceramic bond strength and coefficient of linear thermal expansion difference. J Appl Oral Sci 2009;17(2):122-8. (Crossref)

21. Zhang Z, Tan F, Ba Y and Zhang Y. Effects of different bond agents on commercially pure Ti-porcelain bond strength. Mater. Lett. 2013;109:214-6. (Crossref)

22. Standardization IOf. Dental materials. In: Dentistry Adhesion - Notched-edge shear bond strength test. 2013-06.

23. Papadopoulos T, Tsetsekou A and Eliades G. Effect of aluminium oxide sandblasting on cast commercially pure titanium surfaces. Eur J Prosthodont Restor Dent 1999;7(1):15-21.

24. Toptan F, Alves AC, Henriques B, Souza JCM, Coelho R, Silva $\mathrm{FS}$, et al. Influence of the processing route of porcelain/Ti$6 \mathrm{Al}-4 \mathrm{~V}$ interfaces on shear bond strength. J Mech Behav Biomed Mater 2013;20:327-37. (Crossref)

25. Adachi M, Mackert JR, Parry EE and Fairhurst CW. Oxide Adherence and Porcelain Bonding to Titanium and Ti-6A1-4V Alloy. J. Dent. Res. 1990;69(6):1230-5. (Crossref)

26. Aacute, Squez V, Ouml, Zcan M, Nishioka R, Souza R, et al. Mechanical and Thermal Cycling Effects on the Flexural Strength of Glass Ceramics Fused to Titanium. Dental Materials Journal 2008;27(1):7-15. (Crossref)

27. Lee DH, Lee BJ, Kim SH and Lee KB. Shear bond strength of porcelain to a new millable alloy and a conventional castable alloy. J Prosthet Dent 2015;113(4):329-35. (Crossref)

28. Standardization IOf. Dental materials. In: Dentistry Compatibility testing for metal-ceramic and ceramic-ceramic systems. 2019-10. 